\title{
Saúde, ação pública e território: análise comparativa França e Brasil
}

\section{Health, public action and territory: comparative analysis between France and Brazil}

Philippe Plas - Professor de Sociologia - Université Paris 13 Sorbonne Paris Cité (Centre d'Etudes et de Recherche sur l'Action Locale). Responsável pelo Mestrado 2 em Ciências Políticas: Conselho das Coletividades Territoriais em Estratégia de Desenvolvimento Sustentável. E-mail: philippeplas9@hotmail.fr

Vanderlúcia da Silva Ponte - Professora de Antropologia e História Indígena e do Indigenismo - Universidade Federal do Pará/Campus Bragança - Mestre em Antropologia, doutora em Sociologia pela Universidade Federal do Pará em regime de cotutela com a Université Paris 13 Sorbonne Paris Cité (Centre d'Etudes et de Recherche sur l'Action Locale). E-mail:vantutorapa@gmail.com/vandaponte@ufpa.br

\section{Resumo}

O nível de melhoria de saúde é uma questão importante para os Estados, tanto para os europeus como os que vivem nos países do Sul. O problema de saúde é um grande desafio em todos os lugares. A saúde de uma nação é o resultado da interação de uma variedade de fatores que se relacionam e não somente resultante dos aspectos biomédicos. A partir de uma abordagem comparativa entre a França e o Brasil, este artigo procura colocar em evidência os elementos que formam o sistema de saúde. É necessária uma abordagem local e regionalizada do tema. A desigualdade do território em termos de estado de saúde ou por acesso à saúde é uma realidade, que se apresenta na França e no Brasil. Enfim, um sistema local de saúde pública foi implantado nos dois países, sendo este um ponto comum, no entanto, a lógica de sua implantação parece ser diferente. Com efeito, o sistema francês parece ser mais uma questão de um processo de "bottom-up", do que "top-down", enquanto o inverso é verdadeiro no contexto brasileiro. Esta é provavelmente a razão pela qual o Brasil tem muita distorção entre os modelos de ação legalmente definidos e a realidade da sua implementação, em particular no que diz respeito aos povos indígenas da Amazônia.

\section{Palavras-chave}

Saúde. Desigualdade. Território. Sistema Público Local de Saúde. Indígenas.

\begin{abstract}
The improvement of the health level is an important issue for the States, whether they are european or from the for people who live south. The health gap is a major challenge everywhere. The health of a nation is the result of the interaction of a wide variety of factors, far beyond the biomedical aspects only. From a comparative approach between France and Brazil, this article seeks to highlight the elements which form the health system. It takes a local and regionalised approach. The inequality of the territory in terms of health status or for the access to health is a reality, whether in France and in Brazil. In order to reduce those inequalities, a local system of public health action was implemented in both countries, which is a common point. However, the logic implemented appears to be different. Indeed, the French system seems more a matter of a « bottom-up » process than a « top-down » , while the reverse is true in the Brazilian context. This is probably why Brazil has lots of distortion between action models legally defined and the reality of their implement in the field, particularly regarding to indigenous peoples in the Amazon.
\end{abstract}

\section{Keywords}

Health. Inequality. Territory. A Local System of Public Health. Indigenous. Brazil and France. 


\section{INTRODUÇÃO}

A definição de saúde dada pela Oganização Mundial da Saúde (OMS) é bem conhecida: "a saúde é um estado completo de bem-estar físico, mental e social”. Esta abordagem é interessante, mas ela apresenta o desafio de ser muito difícil de traduzir em indicadores operacionais, é por isso que nossa abordagem se fundamenta sobre uma concepção mais modesta, mais restritiva. Feito isso, pensamos que é preferível falar de estado de saúde ao invés de saúde. A noção de estado de saúde pode, com efeito, ser definida por meio da distribuição estatística de patologias no seio de uma população. Ela pode, igualmente, ser mensurada por meio de uma série de indicadores estatísticos como as diferentes formas de esperança de vida ou a mortalidade perinatal. Tanto a França como o Brasil produzem um relatório da saúde com vários indicadores sobre o estado de saúde da população. Este viés estatístico permite ver as relações mais importantes em função de variáveis objetivas como idade, sexo e profissão. É por meio dessas vairações que aparecem, então, as grandes desigualdades entre os indivíduos, os grupos sociais e os territórios.

Com relação a esta última dimensão, tanto em nível internacional como em nível subnacional, há uma elevada disparidade entre os territórios. É sobre eles que este estudo se interessa mais particularmente, uma vez que associa fortemente sua análise sob o enfoque da Antropologia, da Sociologia e da Ciência Política. A variável do território deve, no entanto, ser analisada com cuidado, na medida em que o território é raramente uma variável ativa em si, mas resultante das relações produzidas socialmente, este parece ser o caso, por exemplo, de certas áreas onde os fatores patogênicos têm mais efeitos que em outras. Podemos citar como exemplo, a zona do Marais, na França, que apresenta um agente de transmissão do mosquito maior que em outras áreas, ou o caso das regiões Norte e Nordeste do Brasil, que em comparação com as demais regiões do país, apresentam os piores indicadores de saúde, dadas as condições sociosanitárias e econômicas encontradas.

Entretanto, o território inclui também as variáveis discriminantes. Socialmente a população é dividida de forma desigual entre os diferentes territórios em termos de desigualdade no que diz respeito ao estado de saúde, isso também é verdade para a variável idade: um bairro com uma população envelhecida irá apresentar maior frequência de patologia do que um bairro com uma população mais jovem.

Não é o efeito intrínseco da variável territorial que nos interessa aqui. Com efeito, o objeto deste artigo concerne mais particularmente sobre a ação 
do território, e notadamente sobre a ação pública. Nosso trabalho se inscreve, portanto, dentro de uma perspectiva que procura analisar um conjunto de elementos que contribuem para a produção do estado de saúde de uma população.

Atualmente, já não é mais possível correlacionar o estado de saúde com simples critérios biomédicos, mesmo se as questões de saúde pública tenham sido baseadas nesse modelo. As descobertas recentes permitem, no entanto, compreender a saúde pública por meio de novos modelos teóricos. Em particular, depois dos anos de 1990, quando Evans, Barer e Marmo (1994) demonstraram que os determinantes sociais, econômicos e culturais têm mais influência sobre o estado de saúde da população do que os componentes dos comportamentos pessoais ou cuidados médicos.

No Brasil, a concepção do fenômeno saúde e doença começa a ser mais abrangente a partir do desenvolvimento do campo da Saúde Coletiva, que como campo teórico-conceitual tem sua emergência iniciada nos anos de 1970, mas se operacionaliza com a Lei Orgânica da Saúde, em 1999, ao contrapor-se ao modelo biologista da saúde pública, já que para a saúde coletiva a análise do fenômeno saúde-doença só pode ser abordada em uma dada coletividade, considerando-se o contexto social, cultural e histórico determinado (NUNES, 2006).

\section{ESTADO DE SAÚDE, INIQUIDADE SOCIAL E AÇÃO PÚBLICA LOCAL}

Em nível mundial, a correlação entre a evolução dos progressos médicos e o estado de saúde da população tem efeitos muito desigualmente distribuídos. Essa desigualdade pode ser mensurada grosseiramente a partir dos dados disponíveis em termos de esperança de vida. Vejamos alguns números sobre esta variável em alguns países: Japão (87 anos), França (83 anos), Somália (52 anos), Brasil (76 anos), 57ํㅡ no ranking mundial dos 182 países, (ONU, 2013). Essencialmente, esta diferenciação entre os Estados mostra que primeiramente há uma separação considerável entre os países do norte e do sul. Entre a Somália e o Japão, por exemplo, percebemos uma diferença na esperança de vida de 35 anos, refletindo, de fato, nas disparidades de desenvolvimento econômico, porque a qualidade de saúde está relacionada com o nível de desenvolvimento econômico medido em termos de Produto Interno Brutio (PIB). A ligação entre a mortalidade e a pobreza está claramente provada. Veremos, mais tarde, que essa relação entre pobreza e doença tem a ver com a incapacidade de acessar cuidados e obter condições econômicas favoráveis em termos de condições de vida. 
Vejamos o caso das populações indígenas da Amazônia. Em comparação com a população infantil brasileira em geral, essa população tem quase duas vezes mais chances de morrer que as demais crianças do Brasil (THOMÉ; SOUZA; CALHEIROS, 2014). Os dados do relatório do Fundo das Nações Unidas para a Infância (UNICEF) mostram que apesar dos avanços no que diz respeito à mortalidade infantil no Brasil, esses avanços não se mostram uniformes, principalmente devido às iniquidades regionais, por raça e etnia. Um exemplo dessa iniquidade pode ser expresso por meio da taxa de mortalidade infantil da população indígena que corresponde a 41,9 por mil nascidos vivos, enquanto a taxa nacional fica em torno de 19,0 por mil nascidos vivos, segundo dados da Pesquisa Nacional por Amostra de Domícios (PNAD) (IBGE, 2009). Entre os anos de 2000 e 2009, foram registrados 6.754 óbitos de crianças menores de um ano de idade. Dentre as causas condicionantes de morbimortalidade em crianças indígenas, a desnutrição ainda é o principal fator.

A pobreza é então um fator de desigualdade mediante a doença. Entretanto, o impacto deste fator é diferente segundo os territórios. De fato, se considerarmos os países com um nível econômico elevado em termos de PIB, veremos que diferenças significativas aparecem dentro deste grupo de países. Por exemplo, os Estados Unidos, considerados a principal potência do mundo, com numerosos prêmios Nobel de medicina, onde os gastos com saúde são os mais altos do mundo, tendo uma expectativa de vida de 78 anos, ocupam apenas o $50^{\circ}$ lugar no ranking mundial em termos de saúde. Este mau desempenho é devido a um sistema de saúde muito desigual, em que muitos grupos populacionais têm pouco acesso aos serviços.

A intervenção pública no campo da saúde continua a ser um desafio importante no que diz respeito ao bem-estar e sua implantação por meio dos diversos sistemas de seguro saúde. O sistema nacional de proteção da saúde da seguridade social continua a ser uma das primeiras condições para garantir todo o estado de saúde de um Estado nacional. Na França, em meados do século XX, a esperança de vida era em torno de 60 anos e ainda estava próxima do nível alcançado no século XIX, notadamente para os homens: um homem de 60 anos poderia esperar viver até 13 a 14 anos (INSEE, 2016). Somente após a Segunda Guerra Mundial é que a esperança de vida começou a aumetar para os homens, em seguida, ela se acelerou progressivamente até alcançar 22,6 anos em 2012, sete anos mais do que em 1962. Este aumento se deve ao sistema de saúde e seguro social, criado em 1947. São as autoridades públicas nacionais, portanto, importantes indutores no sistema de saúde, o que garantiu pela primeira vez a instalação do sistema de seguraridade social, e permitiu a igualdade dos cidadãos 
no que diz respeito ao acesso aos cuidados de saúde, uma condição essencial para que se possa obter beneficios dos avanços na medicina.

Entretanto, o sistema nacional não garante totalmente a igualdade dos cidadãos face à saúde. Em cada Estado é possível constatar fortes disparidades entre os territórios. Na França, por exemplo, entre a região Norte e a região dos Rhône Alpes (Lyon) a diferença na expectativa de vida é de 5 anos, o que é muito considerável. Mas ainda aparecem as desigualdades territoriais, dependendo da unidade territorial escolhida para a comparação entre a maior (região do mundo) para o menor (bairro de uma cidade).

No Brasil, segundo dados do Instituto Brasileiro de Geografia e Estatística (IBGE, 2013), a unidade federativa com o maior valor na expectativa de vida era Santa Catarina, cujo índice era de 78,14 anos de idade, seguida pelo Distrito Federal (77,3 anos). O Maranhão era o estado com o menor valor (69,7 anos). Entre as regiões do país, o Sul tinha a maior esperança de vida $(80,3)$ e o Norte a menor $(75,3)$. Entretanto, se compararmos os dados entre os municípios da região Norte, por exemplo, a diferença na espectativa de vida entre os maiores e os menores, se acentua. Para compreender essas desigualdades e disparidades, é necessário se interrogar sobre os mecanismos que a sociedade produz para contribuir com o estado de saúde. Por ora, nós vamos mencionar apenas dois fatores que são, provavelmente, os mais óbvios, para demonstrar tais disparidades, o nível de conhecimento biomédico e o sistema nacional de seguridade social. Mas o que podemos chamar de sistema de saúde é um conjunto multifatorial em que cada elemento desempenha um papel fundamental (SAINT PAUL, 2013).

\section{O PROCESSO DE DESCENTRALIZAÇÃO E A AÇÃO PÚBLICA LOCAL DA SAÚDE}

A existência de legislação e de mecanismos nacionais de proteção social não é suficiente, todavia, para garantir a igualdade dos cidadãos do ponto de vista da saúde. Na França, embora o sistema de proteção social exista há muito tempo, as desigualdades persistem e, em algumas situações, estão se ampliando. Para encontrar as soluções, é necessário admitir a ideia de que o funcionamento do sistema de saúde tem um componente territorial muito importante. O estado de saúde de uma população é resultante de um sistema de ação que associa uma pluralidade de atores sobre um território. A intervenção pública nacional não é suficiente. Há uma dimensão local de estado de saúde. Nós podemos falar de sistema público local de saúde. 
Em relação à dimensão local, é preciso sublinhar que a questão da saúde está vinculada mais amplamente ao movimento de descentralização que afetou numerosos territórios, depois dos anos 1930, tanto na França como na África ou na América Latina. Esta lógica de descentralização modificou gradualmente as modalidades de governança territorial. Este é um novo contexto político. Nós assistimos cada vez mais à instalação da lógica de territorialização da ação pública. Mas, geralmente, esse fenômeno advém em consequência do modelo dominante da sociedade industrial que foi em todos os lugares acompanhado por um fortalecimento do papel dos Estados, após a implementação de políticas econômicas keynesianas, tendo em vista a construção do modelo do Estadoprovidência.

Em todos os lugares, o Estado entrou em crise, se tornou cada vez mais incapaz de responder às dificuldades sociais e econômicas, incapaz também de atender as soluções intervencionistas, tendo em vista que suas medidas tornaramse inapropriadas à resolução dos problemas. Por um longo tempo, também a sociologia das organizações (BURNS; STALKER, 1961; LAWRENCE; LORSCH, 1967) mostrou que o universo centralizado e burocrático só foi eficaz em um ambiente estável. Mas a instabilidade pode ser menor e mais eficaz devido a sua reactividade estrutural e sua capacidade de resposta às mudanças no ambiente que é, geralmente, lenta. Em relação à ação pública, é a ascenção do agir local e a consequente perda de eficiência do Estado centralizado que produz um contexto de maior incerteza.

O desenvolvimento da ação pública local se constitui por meio do desenvolvimento de duas lógicas convergentes. Dentro dos grandes sistemas burocráticos, nós assistimos cada vez mais às tentativas de modernização das práticas, as quais se configuram de procedimentos menos complexos e com possibilidades de maiores iniciativas para os agentes agirem (LE GALÈS; THATCHER, 1995). Na França, depois do fim dos anos 1980, a questão da modernização do Estado é recorrente. Ela substitui uma "lógica de responsabilidade", quando os agentes se adaptam à situação, pela "lógica de procedimento", quando os agentes respeitam as regras burocráticas, segundo os termos da circular de Rocard (Primeiro Ministro da França), relativa ao serviço de renovação público de 23 de fevereiro de 1989, circular que se pronuncia em favor do desenvolvimento das responsabilidades de autonomia dos serviços e instalação, enfim, demanda a exigência de uma avaliação sistemática das políticas públicas (BARUCH; BEZES, 2006).

Por outro lado, observamos em toda parte uma dinâmica de pesquisa de avaliação dos modos de trabalho e de intervenção do setor público sobre 
os territórios, tornando as autoridades estaduais e locais mais reativas. As modalidades de ação dos poderes públicos são, portanto, engajadas no processo contínuo de transformação de suas modalidades de intervenção. A segunda lógica modernizadora é o desenvolvimento da descentralização, considerada uma dimensão fundamental das modalidades de ação da modernização. Esse processo é ainda reforçado pela ascenção do poder de novos atores no sistema de ação local, associações, população, setor privado. O sistema de ação local é, portanto, progressivamente, constituído de uma pluralidade de atores. Em consequência, a ação local torna-se mais e mais o produto da combinação destas configurações de atores (TEISSERENC, 2002).

No Brasil, o processo de modernização do Estado começa a se desenhar nas décadas de 1980 e 1990, e uma nova estrutura das políticas públicas começa a se operar a partir das grandes mudanças que ocorrem em nível mundial. Segundo Abrucio (2007), o contexto desse período mostra um país recém-saído do regime militar, que ainda enfrentava muitos desafios históricos, entre eles o descontrole financeiro, a falta de responsabilização dos governantes e dos burocratas perante a sociedade, a politização indevida da burocracia nos estados e municípios, além da fragmentação excessiva das empresas públicas, com a perda de foco de atuação governamental.

As conferências de Alma-Ata e do Canadá (FERREIRA E BUSS, 2001) realizadas, respectivamente, nos anos de 1981 e 1986, propagaram ideias e princípios que marcaram sobremaneira a condução da política de saúde no Brasil, acabando por constituir-se como alicerces doutrinários do Sistema de Saúde Público Brasileiro, o Sistema Único de Saúde (SUS). Elas contrapunhamse aos paradigmas anteriores e defendiam a ideia de que era necessário reduzir as iniquidades sociais para promover a saúde como um componente essencial para o desenvolvimento humano.

$\mathrm{Na}$ conferência de Alma-Ata, sobretudo, da qual o Brasil é signatário, definiu-se que o modelo de saúde deveria obedecer aos princípios de atendimento universalizado e hierarquizado, a partir de processo de descentralização das ações e dos serviços de saúde, de forma equânime. A partir dessa conferência defendia-se que, para se obter saúde, há de se fazer um esforço conjugado entre os setores sociais e econômicos, além de acentuada participação da comunidade local na planificação e organização dos serviços de saúde (FERREIRA; BUSS, 2001). Tal medida influenciou sobremaneira a formulação das Leis Orgânicas da Saúde (LOAS) e determinou fortemente o processo de municipalização da saúde brasileira.

No Brasil, as Leis Orgânicas da Saúde vieram, por um lado, proporcionar oportunidades de participação cidadã e potencializar práticas locais, conforme 
apontam os estudos de Abrúcio (2007), como também contribuir para impulsionar novos conflitos e problemas, como o crescimento exagerado de municípios, a pouca articulação intergovernamental e a manutenção do patrimonialismo local.

A construção da Política de Atenção à Saúde dos Povos Indígenas no Brasil, por exemplo, emergiu no bojo das discussões sobre os efeitos nefastos do modelo neoliberal, que defendia uma participação mínima do poder público nas políticas sociais, entre elas a da saúde, em um momento em que ainda se faziam sentir fortemente os efeitos do movimento indígena que se consolidou, após a instalação da Constituinte e da consagração na Carta Magna, que veio garantir os direitos dos povos indígenas de todo o país.

Trata-se de um momento político, que deve ser analisado também em função do crescente processo de participação e de organização dos povos indígenas em toda a América Latina, processo este que teve forte influência sobre os textos constitucionais e também sobre as declarações das Organizações das Nações Unidas, em particular aquelas que se referem aos princípios de tolerância e multiculturalismo étnico, expressos nas convenções da Organização das Nações Unidas para a Educação, a Ciência e a Cultura (UNESCO), e na Convenção 169 da Organização Internacional do Trabalho (OIT).

Nos novos textos constitucionais, a força do movimento indígena se expressou nos artigos que fazem referência à garantia dos direitos das populações indígenas e reconhecem os grupos étnicos como povos diferenciados culturalmente da população brasileira. É a partir deles que se desencadeia o processo de elaboração de outras legislações e normas legais que reconhecem a diversidade cultural do povo brasileiro. A decisão política do governo brasileiro de implantar o Subsistema de Saúde Indígena, a "educação e a saúde diferenciada", cria novas condicionalidades institucionais para a inserção desses grupos em políticas públicas específicas.

Não se pode deixar de mencionar também, como lembra Garnelo (2006), que a política de saúde para as minorias étnicas no Brasil se relaciona também com os apelos internacionais direcionados para a preservação dos recursos naturais, uma vez que esta serve de contraponto às mudanças climáticas globais, capazes de ameaçar a vida planetária. Nesta perspectiva, as populações indígenas passam a ser vistas como parte integrante de ecossistemas ameaçados e, por conta disso, passam a convocar as comunidades internacionais para a preservação de suas culturas.

Com a realização da segunda Conferência de Saúde Indígena, em 1993, esses apelos ambientais, mas também o reconhecimento dos direitos das minorias étnicas, já estavam bastante consolidados, permitindo que se desenhasse um 
sistema de saúde sensível às particularidades culturais desses grupos. Destaque especial deve ser dado às recomendações direcionadas à criação dos Distritos Sanitários Especiais Indígenas (DSEI), assim como à participação dos grupos étnicos nas atividades realizadas pelos distritos, com a efetivação e implementação dos DSEI em 1999 (MENDES, 1999).

Garantir o reconhecimento da "saúde diferenciada" aos povos indígenas e descentralizar os serviços para o mais próximo das populações, no caso das populações indígenas, não significou melhor resultado dos serviços de saúde e nem melhores respostas às demandas dessas populações, senão acirrou anda mais os conflitos subjacentes entre as populações indígenas e os atores locais, justamente porque a configuração do poder local propiciou novos conflitos entre gestores locais, muito deles antigos antagonistas das populações indígenas, com os quais disputavam o território e grande parte de seus recursos naturais.

A descentralização não é somente uma mudança de escala: a passagem do nacional ao local, ela é uma das orientações estratégicas da modernização da ação pública. A condição, contudo, se articula com uma abordagem de transformação das práticas. Com efeito, o setor público, quer seja nacional ou local, gera modelos de ação análogos. Prefeitura ou serviços de Estado funcionam da mesma maneira e segundo as lógicas onde dominam o regulamento e a burocracia. Esse funcionamento fica um pouco reativo e encontra dificuldades de inovação. A descentralização constitui, de fato, em uma das dimensões da avaliação das práticas dos atores públicos.

\section{O SISTEMA DE ATOR E A QUESTÃO DO TERRITÓRIO}

Progressivamente, emergem novas formas de intervenções da ação pública que tende a configurar em nível de Estado as coletividades territoriais. Em relação a essas novas lógicas, Donzelot e Estebe (1994) chamam de "Estado animador" em razão do Estado desempenhar esse novo papel. Patrick Hassenteufel prefere chamar de "Estado regulador" (HASSENTEUFEL, 2011). Isto significa, com efeito, que o ator público não é mais somente ator da ação pública, mas que passa a desempenhar um papel essencial, um papel de mobilização, de indultor e de orientação ou de coordenação. Esse processo se instala dentro do sistema de ação pública. É necessário utilizar o termo "ação pública” no plural, porque não há um único sistema nessa nova configuração, mas ao contrário, uma multiplicidade de sitemas de ação, organizados a partir de um tema. Neste contexto, o papel majoritário do ator público será bem identificado, ou seja, de mobilizar e coordenar o conjunto de atores em torno de um projeto. 
Podemos exemplificar esse novo sistema a partir do caso brasileiro, dentro das comunidades indígenas. No Brasil o sistema se apresenta como um sistema diferenciado de saúde, denominado Subsistema de Saúde Indígena, ainda que ele esteja vinculado ao sistema geral de saúde da população brasileira, ele surge da força e da potência do movimento indígena, que de forma articulada criou condições políticas para a criação de um Subsistema de Saúde Indígena particular.

No caso específico da Política de Saúde Indígena e nos rumos tomados pela política indigenista brasileira, segundo Gonçalves (2010), o processo de descentralização cria uma rede complexa de atores associada à maior participação da sociedade civil, e do aumento de parcerias do setor estatal com o setor privado, provocando mudanças significativas nas relações interétnicas. Nos termos dos quais se serve a autora, é nos anos de 1990, que podemos melhor visualizar seus primeiros efeitos, pois há uma conjugação de eventos e situações que é colocada em cena, em especial, a criação da política de redução da máquina estatal e da terceirização de serviços.

Com a implantação da política indigenista, a ação antes empreendida com exclusividade pela Fundação Nacional do Índio (FUNAI) é transferida para a responsabilidade de diferentes órgãos dos governos federal, estadual e municipal. Por meio da parceria público-privado, as organizações não governamentais, as associações indígenas, as universidades e os movimentos sociais assumiram a execução dos serviços de saúde nas aldeias.

A transferência de competências da esfera federal para a estadual e a municipal ou para as organizações não governamentais, sobretudo as associações indígenas, cria novas condicionalidades institucionais e, portanto, uma nova configuração política na cena local decorrente da ampliação do leque de atores que passam a interagir, não só na promoção de ações e serviços para as populações indígenas, mas também nas arenas de embate e conflito entre universos antagônicos e interesses divergentes.

Não podemos esquecer, além disso, as disputas institucionais e de poder que se acirraram entre as instituições que intervinham no campo indigenista. Nesse aspecto, foi bem evidente a considerável perda de poder da FUNAI quando da transferência da saúde para a Fundação Nacional de Saúde (FUNASA) que, na tentativa de fortalecer-se institucionalmente, adotou mecanismos e buscou engendramentos administrativos, que acirraram ainda mais as tensões entre os atores.

Foi assim que, gradativamente, se fizeram sentir na cena local manifestações das "lideranças indígenas", que buscavam um protagonismo que lhes permitisse fortalecer sua autonomia e participação no campo das políticas públicas. Como 
elemento dessa mesma dinâmica de reocupação da cena, foram se manifestando também, mais e mais, lógicas diferenciadas do saber-fazer da coisa pública. Pouco a pouco, foram colocados em xeque, não apenas as tradições dos grupos indígenas que, no cotidiano das aldeias, operam com uma lógica local, nas quais questões burocráticas e administrativas são resolvidas de forma consensual, por meio de diálogos e reuniões comunitárias, mas também o modo de fazer da gestão pública, baseado na burocracia e no ato jurídico.

O sistema de ação local em diferentes domínios se apoia sobre múltiplas dimensões (LE GALÉS ; THATCHER, 1995). Uma das dimensões é institucional uma vez que se associa a diferentes atores em dinâmica comum. É necessário, assim, reunir esses atores dentro de um dispositivo que permita a permanência da ação. Essas estruturas podem ser mais ou menos permanentes e duráveis segundo a ação ou projeto ou sua durabilidade, inscritos em uma temporalidade longa. Por exemplo, um projeto de renovação do bairro e um projeto territorial de saúde se inscrevem em temporalidades diferentes.

Pouco a pouco é um novo modelo de ação nas políticas públicas que se instala. A decisão e a condução da ação pública tornam-se um processo cada vez mais coletivo, que mobiliza igualmente as identidades territoriais na medida em que tende a colocar a população que ocupa o território à agir. A dimensão identitária é essencial nesse processo de mobilização.

O campo que nos interessa aqui, o da Saúde, o estado de saude do território é a resultante do sistema de ação local da saúde. Este é particularmente complexo e diversificado, a questão da saúde é uma ação pública transversal que mobiliza numerosos atores da ação pública. O domínio é mais vasto que o estado de saúde de uma população e não depende unicamente da ação de um objeto principal da saúde. Todos os elementos que organizam o ambiente cotidiano dos indivíduos exercem uma influência sobre o estado e saúde. Consideremos um exemplo: na Europa, e na França, em particular, certas doenças temidas como a febre tifóide são hoje totalmente erradicadas, e o progresso médico está longe de ser o único vetor deste sucesso. De fato, o resultado foi alcançado pela generalização da utilização da água potável e do tratamento de seus resíduos. A bactéria responsável pela doença está presente na água, sendo uma das medidas essenciais de sucesso do ponto de vista da saúde pública melhorar a qualidade da água doméstica. Só a dimensão local permite uma adaptação pertinente às especificidades dos territórios e das populações. A relação da saúde varia muito em função das categorias e das particularidades culturais às quais as populações pertencem. 


\section{O SISTEMA LOCAL DE SAÚDE}

O sistema local de saúde funciona através de uma articulação que se opera por meio da mesma dinâmica e por meio de múltiplos sistemas particulares (UNGER, 2010). Ele possibilita à ação pública local organizar e coordenar esses diferentes sistemas. Veremos que algumas abordagens mais conhecidas, de maneira geral, concebem o território de forma burocrática, entretanto, o território não funciona dessa maneira.

São nas comunidades locais que a lógica de parceria constrói um sistema que busca dar respostas para os problemas específicos de cada território. Tanto na França como no Brasil nós encontramos grandes dificuldades de operá-lo nas zonas rurais, normalmente, é difícil de encontrar profissionais de saúde que aceitem se instalar no espaço rural. No Brasil, o governo brasileiro tomou a inicitiva de contratar médicos estrangeiros para trabalhar nas zonas rurais e suprir essa lacuna nos serviços de saúde, mas geralmente, como é o caso da França, são as coletividades territoriais que se mobilizam para solucionar esse problema.

$\mathrm{Na}$ França, as coletividades territoriais criaram em 2007 uma nova instituição, a "casa de saúde", que muito rapidamente se desenvolveu. Embora o Estado a tenha apoiado financeiramente, ela continua ser uma iniciativa local e são as coletividades que detêm a responsabilidade sobre elas. As "casas de saúde" são estruturas multiprofissionais com personalidade jurídica e constituídas por profissionais médicos, auxiliares médicos ou farmacêuticos. Os profissionais de saúde exercem seus cuidados de saúde (principalmente os profissionais liberais) por meio de projetos de saúde e sob sua coordenação. As "casas de saúde" são vinculadas à Agência Regional de Saúde por meio de um contrato plurianaual, com objetivos e metas, antes de qualquer pagamento ou contribuição financeira à agência. Este é um exemplo de parceria público/privado onde os profissionais (médicos, enfermeiros, fisioterapeutas e farmacêuticos mantêm totalmente seu status liberal). Em janeiro de 2012 existiam 235 "casas de saúde" em funcionamento e aproximadamente $450 \mathrm{com}$ projetos identificados. Elas são em maior frequência localizadas em áreas rurais (80\%). As "casas de saúde" têm 2.650 profissionais, incluindo 750 médicos.

A intervenção em nível local deve permitir uma melhor maneira de se adaptar à oferta/demanda local. É por isso que práticas como o diagnóstico de saúde local vivida pelas cidades de Valência ou Chamberie, no sul da França, são particularmente úteis. O diagnóstico local de saúde é realizado, combinando abordagens quantitativa (análise de indicadores sócio-demográficos, sanitários e ambientais) e qualitativa com uma larga implicação dos atores e dos habitantes 
residentes em toda a cidade e bairros, e também uma reflexão sobre a criação de um sistema de observação permanente para o "pós-diagnóstico".

O diagnóstico local de saúde tem como objetivo identificar as necessidades da população da área observada e avaliar a forma como a política de saúde e as ações implementadas pelos diversos atores estão respondendo às necessidades dos residentes. Tal ação tem o propósito de examinar os resultados das ações executadas e aperfeiçoar as ações desenvolvidas pelos parceiros. O diagnóstico de saúde é, antes de tudo, útil no planejamento, um componente da abordagem do projeto que permite refinar as orientações da ação pública. Mas, geralmente, esta abordagem se articula com outras políticas públicas direcionadas aos bairros em condições sociais desfavoráveis, tal qual a política da cidade em relação aos dispositivos locais como os "Ateliers Santé Ville". Por seu papel de coordenador, o "Atelier Santé Ville" criou um espaço permanente de reflexão e ação entre atores de diferentes setores e favorece atividades multidisciplinares que possibilitam uma complementariedade de respostas e oportunidades de trabalho participativo. Ao mesmo tempo, criou espaço e tempo para reunir e estimular a participação ativa dos habitantes, a fim de estar mais próximo das necessidades identificadas localmente e melhor atendê-las.

É, igualmente, nesse contexto local que, em 2009, nova ferramenta da ação local aparecem: o controle local da saúde. Ele foi construído a partir do diagnóstico participativo, compartilhado e elaborado pela Agência Regional de Saúde (ARS), a autoridade local competente e os seus parceiros para descrever a situação sanitária, econômica e social e produzir o processo de saúde de um dado território.

Pelo diálogo e a dimensão de parceria que ele aporta, o controle local de saúde é um lugar de expressão da democracia sanitária, na implementação prática de uma abordagem de saúde geograficamente direcionada e adaptada às necessidades de saúde das "populações mais vulneráveis". As agências funcionam como um lugar de encontro entre a política de saúde elaborada pela ARS e aquelas desenvolvidas pelas coletividades territoriais e seus parceiros, notadamente a política urbana.

Além destas características gerais de sistemas mais específicos, também foi criada a "Assembleia Ordinária" para apoiar segmentos específicos da população. Por exemplo, uma rede de gerontologia que reúne um conjunto de interveções para a pessoa idosa com certa dependência. Essas habilidades sanitárias e sociais complementares são coordenadas por meio dessa rede e suas ações. A meta da rede é possibilitar respostas adaptadas às necessidades das pessoas idosas, que desejam continuar a viver em casa em condições sociais adequadas de saúde. Por 
meio da rede, nós encontramos os profissionais liberais de saúde e paramédicos, em um hospital próximo (hospital local, hospital central) e um Serviço de Cuidados de Enfermagem em Domicílio (SSIAD), assim como um assitente social.

Do mesmo modo, podemos igualmente mencionar a Proteção em Saúde Materna e Infantil (PMI), que é um sistema de proteção à mãe e à criança criado em 1945. Esse serviço se organiza por meio de consultas e de ações de prevenções médico-sociais em favor das mulheres grávidas e de crianças menores de 6 anos.

Ele também desempenha um papel vital na prestação da assistência às crianças: orientações das demandas de assitência materna, realização de ações de formação, vigilância e controle das assistências maternas, bem como o estabelecimento e serviços de acolhimento às crianças menores de 6 anos. Todos esses dispositivos têm o mesmo objetivo: assegurar uma gestão mais próxima das questões de saúde das populações e das demandas tanto médicas como sociais.

Para alcançar esses objetivos, o sistema de saúde se apoia sobre o sistema de ação social que desempenha um papel importante na assistência às famílias em condições sociais mais precárias.

No Brasil, segundo Mendes (1999), o sistema local de saúde se estrutura a partir do Movimento pela Reforma Sanitária, constituído por pesquisadores, professores, residentes, trabalhadores da saúde, políticos e militantes de esquerda, que buscavam garantir a saúde como direito social de forma equânime e universal (MADEL, 1991).

Nessa arena política duas tendências estavam em disputa no projeto da reforma sanitária brasileira. De um lado, uma tendência à privatização e internacionalização dos serviços de saúde e, de outro, uma tendência à estatização e nacionalização desses serviços. Por trás dessa questão de base estavam postas outras disputas, entre elas a da gestão do sistema, a do financiamento, a da maior ou menor medicalização das doenças advindas das questões sociais, o ato médico, a integração e a hierarquização dos serviços por nível de complexidade desde os mais simples, com resolutividade na Atenção Primária, até os mais complexos, com necessidade de intervenção hospitalar de alta tecnologia.

Garnelo (2004) enfatiza que, entre as propostas relevantes para a Reforma Sanitária, ganhou destaque a recomendação da garantia de oferta de atenção à saúde de qualidade para todos os grupos populacionais do território nacional, entre eles o grupo das populações que viviam em situação de pobreza e em regiões de difícil acesso, como é o caso da maior parte da população indígena, razão que pela qual foi criado o Subsistema de Saúde Indígena, em 1999. Nesse sentido, diz a autora, a preocupação de prestar assistência de forma universal com prioridade 
para a Atenção Primária a todos os lugares e a todos os grupos populacionais do país, incluindo-se os que não tinham empregos formais ${ }^{1}$, caracteriza o SUS como uma política de proteção social, e, portanto, comprometida com a redução da desigualde social.

A cobertura universal preconizada pelo SUS com prioridade para Atenção Primária, no entanto, atendeu a um apelo e às recomendações da Organização Mundial da Saúde por uma oferta de serviços capazes de garantir um atendimento eficiente, com elevada capacidade resolutiva das necessidades de saúde, com menor custo, mediante a adoção de técnicas simples, suficientes para responder aos principais problemas de saúde que acometem a população ${ }^{2}$.

Estas recomendações tiveram uma grande e significativa influência sobre a concepção e criação do SUS e sobre as Leis Orgânicas da Saúde. A Lei no 8.080/1990, que define como sendo de responsabilidade do Estado todo um conjunto de ações de saúde, cuja execução, deve obedecer a descentralização político-administrativa do SUS e operacionalizado por meio das esferas federal, estadual e municipal. Já a Lei no 8.142/1990 garante o processo de participação e controle social e o repasse regular e automático de recursos do Fundo Nacional de Saúde para os Municípios, os Estados e o Distrito Federal (BRASIL, 1990).

A Lei n⿳o 8.080/90, já prevista na Constituição de 1988, define e dá a diretriz do funcionamento do Sistema Único de Saúde que, em sua premissa, estabelece a saúde como direito universal, e deve ser coordenado em comando único pelo Ministério da Saúde e organizado por meio dos Distritos Sanitários, com a fiscalização e controle social dos Conselhos de Saúde.

O Distrito Sanitário, de acordo com Mendes (1999), deve estar vinculado à microrregião, devendo ser hierarquizado. Nele, portanto, os serviços de saúde devem ser organizados de acordo com o nível de complexidade tecnológica, do menos ao mais complexo, configurando uma estrutura piramidal ${ }^{3}$. Além do mais,

1 Os serviços de saúde anteriores ao SUS prestavam assistência à saúde de forma regulada, ou seja, somente para os trabalhadores que tivessem vínculo formal de trabalho e pagassem os tributos para a Previdência Social, o restante da população era assistido pelas Santas Casas de Misericórdias, de cunho filantrópico e beneficente.

2 No campo sanitário há, no entanto, disputas em torno da concepção acerca da Atenção Primária. Há uma tendência que reduz a Atenção Primária a uma lógica mercadológica (lógica do welfare state) que concebe esses serviços como de menor custo. Esse tipo de serviço seria voltado para as populações desprovidas de recursos materiais e econômicos. Por outro lado, há outra tendência que considera a Atenção Primária de baixa complexidade tecnológica, mas de alta complexidade cognitiva e alta resolutividade, porque parece capaz de reduzir em $80 \%$ os agravos de saúde, uma vez que se compreende os determinantes do processo saúde-doença como advindos de causas sociais, econômicas, políticas e ambientais. Para maiores informações, consultar Mendes (1999; 2012).

3 Para maiores informações sobre as diferentes concepções sobreos modelos de saúde e redes de serviços, consultar Mendes (2012). 
como determina a normatização do SUS, os serviços e as ações de saúde devem obedecer a uma ordem progressiva de descentralização de poder. Isso significa que embora haja responsabilidades sanitárias bem definidas para cada um dos três entes federados (federal, estadual e municipal), a gestão da saúde deve buscar obter a municipalização plena da oferta de serviços. Isso porque predomina um entendimento coerente com recomendações internacionais baseadas na ideia de que as ações de saúde se farão mais eficazes quanto mais próximo estiverem os serviços de saúde da população usuária do sistema e dos problemas que determinam os processos de saúde-doença ${ }^{4}$ forem organizados os seus serviços de saúde.

Os Conselhos de Saúde, por sua vez, são instâncias de participação, por meio das quais se deve fiscalizar e exercer o controle social da execução da política de saúde, conforme determina a Lei no 8.142/1990. Sua composição deve ser paritária, e deve incluir representantes dos usuários dos serviços do SUS, representantes de trabalhadores do sistema, representantes dos movimentos sociais e representantes dos prestadores de serviço e entidades privadas da área da saúde. Os conselhos de saúde operam nos três níveis do sistema de saúde, ou seja, na esfera nacional, estadual e municipal. Geralmente contam com a participação de comissões técnicas, que podem apoiar os conselheiros em suas avaliações e tomadas de decisões.

Além dos Conselhos de Saúde, outras instâncias que fortalecem o funcionamento do SUS e garantem o processo e descentralização do sistema são os fóruns de pactuação e articulação técnica e política da gestão, denominados de Conselho Nacional de Secretários Estaduais de Saúde (CONASS) e o Conselho Nacional de Secretários Municipais de Saúde (CONASEMS). Esses dois fóruns têm importante papel estimulador na consolidação e descentralização do SUS e funcionan como instâncias de articulação entre os diferentes níveis de gestão do sistema tanto no âmbito estadual, por meio das Comissões Bipartites, como no âmbito federal, por meio da Comissão Tripartite. Essas comissões têm a responsabilidade de orientar os gestores na tomada de decisão, devendo suas pactuações e acordos receberem o referendo ou a homologação do respectivo Conselho de Saúde.

Tanto os Distritos Sanitários, como os Conselhos de Saúde e toda a lógica que conduz o modelo de saúde do SUS, em especial no que se refere à municipalização, a ênfase na Atenção Primária em Saúde e na forma como

\footnotetext{
O processo saúde-doença se entende aqui como aquele relacionado ao modelo da biomedicina que considera como fatores determinantes ao adoecimento as condições socioeconômicas e ambientais.
} 
se estrutura a Estratégia Saúde da Família ${ }^{5}$ foram adaptados para a realidade indígena. Isso implicou numa série de controvérsias, impasses e conflitos, que até hoje ainda se fazem sentir nos espaços de interlocução entre gestores do SUS e as populações indígenas. Além disso, implicou na forma como o mercado e o Estado operacionalizaram e exerceram o controle sobre a saúde da população brasileira. Com a implantação do SUS, estabeleceu-se um campo de forças entre a esfera pública e privada que teve grande influência na execução da política de saúde brasileira e, em particular, na Política de Saúde Indígena.

No início de 1990, em razão de cortes orçamentários ${ }^{6}$, mas também por deficiência de servidores públicos e da capacidade institucional instalada, os entes federados se viram obrigados a terceirizar os serviços e a transferir as ações de saúde para o setor privado, passando a executar as intervenções de saúde de forma pontual, direcionada primordialmente para grupos especiais ou em condições de "vulnerabilidade social"", como velhos, mulheres e crianças, povos indígenas e população abaixo da linha da pobreza e/ou as pessoas atendidas por programas vinculados às doenças de impacto endêmico e epidêmico (GARNELO, 2004), como hanseníase, tuberculose, hipertensão arterial, diabete, dentre outras. Desnecessário dizer aqui, que esta tendência à terceirização e transferência de funções do Estado para o setor privado entrou em rota de colisão com os movimentos sociais, defensores da reforma sanitária e com os partidários da saúde como direito social a ser garantido por meio de ações do Estado, como preveem a Constituição e a Lei Orgânica da Saúde.

Como fazem ver os estudos de Faleiros (2004), trata-se de uma tendência que se intensificou no governo de Fernando Henrique Cardoso (de 1995 a 2003) que, mais e mais, propagou fórmulas de ação pública desenvolvidas em parceria

5 A Estratégia Saúde da Família na concepção mais progressista dos teóricos do campo da saúde deve se constituir em uma prática estruturante e modelo substitutivo da Atenção Primária em Saúde, devendo ser o contato preferencial e porta de entrada da rede de serviços. A atenção à saúde deve ser realizada por equipe multiprofissional composta de: médico, enfermeiro, técnicos de enfermagem e agentes de saúde, apoiados por uma equipe de especialistas por meio do Núcleo Atenção à Saúde da Família. A ESF deve funcionar interligada em rede assistencial de baixa, média e alta complexidade, de forma a garantir atendimento integral e obter $80 \%$ de resolutividade dos problemas de saúde. No entanto, na maioria dos municípios, o que se vê são práticas pontuais voltadas para populações consideradas de risco social, com baixa cobertura populacional e pouca resolutividade. Para melhor aprofundamento do tema consultar: (GIOVANELLA; MENDONÇA, 2009).

6 O Plano Diretor de Reforma do Estado (PDRE) veio reduzir a intervenção do poder público na cena social. Ver Garnelo (2004).

Esse termo é introduzido principalmente por programas financiados pelo Banco Mundial, que classifica as populações pelas condições socioeconômicas e pela situação de risco social. Geralmente essa classificação leva em consideração as variadas situações de exposição desses grupos para determinados agravos de saúde, situações de violência, uso de drogas, marginalização, dentre outros. 
com o setor privado, incentivando o aumento significativo das organizações sociais (OS) e das organizações da sociedade civil de interesse público (Oscip), herdeiras de um modelo de gestão regulador do mercado, baseado na relação público-privada (PPP).

Desde de 1991, por meio das Normas Operacinais Básicas ( NOB 01/91 ${ }^{8}$, NOB 01/92, NOB 01/93 e a NOB 01/96 até a Norma Operacional de Assistência à Saúde (NOAS) (Portaria MS/GM no 95/2001), o Instituto Nacional de Assistência Médica da Previdência Social (INAMPS) e o Ministério da Saúde implantaram várias medidas administrativas que possibilitaram acelerar o processo de regionalização e descentralização da saúde, contribuindo para a elaboração dos planos diretores de regionalização ${ }^{9}$, investimentos e Programação Pactuada e Integrada ${ }^{10}$. Esse processo contribuíu de forma significativa para melhorar o acesso aos serviços de saúde para a população brasileira, mas de fato, não representou uma melhora da assistência prestada, já que os gastos com serviços providos e de alta complexidade se mantiveram em ascenção.

Com o Pacto pela Saúde, criado em 2006 (Portaria n 399/2006), na gestão do presidente Luis Inácio da Silva se estabelece um conjunto de prioridades a serem assumidas pelos gestores das três esferas (municipal, estadual e federal). As prioridades estão expressas em objetivos, metas e indicadores, que são definidas nacionalmente, mas que permitem que os gestores municipais e estaduais complementem ações a partir da realidade local.

Com a efetivação desse pacto, pretendia-se reforçar a organização das regiões sanitárias (regionalização) instituindo mecanismos (colegiados) de cogestão e planejamento regional; qualificar o acesso ao direito humano à saúde; redefinir instrumentos de regulação, programação e avaliação; valorizar a cooperação técnica entre os gestores; unificar os diversos pactos existentes; estimular o financiamento tripartite com critérios de equidade nas transferências fundo a fundo e fortalecer o controle social (BRASIL, 2006).

8 A NOB 01/91 ainda foi emitida pelo antigo órgão responsável pela gestão de saúde, denominado Instituto Nacional de Previdência Social (INAMPS), mas, as demais NOB foram emitidas pelo Ministério da Saúde, atual órgão gestor da saúde nacional.

9 A elaboração do Plano Diretor de Regionalização consiste em um processo, coordenado pela SES e que envolve o conjunto de municípios, de delimitação de regiões de saúde que, sob a responsabilidade do Estado, realiza o planejamento das ações/serviços de saúde com enfoque territorial-populacional, não necessariamente restrito à abrangência municipal, mas respeitando seus limites e a autoridade do gestor municipal, que garanta níveis adequados de resolução dos problemas de saúde da população (BRASIL, 2001).

10 É um instrumento essencial de reorganização dos modelos de atenção e de gestão do SUS, de alocação dos recursos entre municípios e de explicitação da distribuição de competências entre as três esferas de governo. A PPI traduz as responsabilidades de cada ente gestor do sistema (SMS e SES), com a garantia de acesso da população aos serviços de saúde, quer pela oferta existente no território de um município específico, quer pelo encaminhamento aos municípios de referência (sempre mediadas por relações entre gestores (BRASIL, 2001).

Novos Cadernos NAEA • v. 20 n. $1 \bullet$ p. 43-66 • jan-abr 2017 
Mesmo que se tenha criado diferentes mecanismos legais e operacionais para dinamizar o processo de descentralização e regionalização dos serviços de saúde para os municípios, esses mecanismos não tiveram os mesmos efeitos nos diferentes territórios. Uma pesquisa coordenada por Costa (2014) mostra, por exemplo, que no estado do Pará, o perfil de mortalidade é mais elevado para a população que depende do SUS. Uma das razões, segundo o estudo, pode estar relacionado ao arranjo produtivo local de saúde que, em 2008, representava 4,9\% do PIB do estado do Pará. Em 2012, com redução para 4,5\%, esses valores corresponderam às menores taxas de investimento, de acordo com recomendações dadas pela Organização Mundial da Saúde para os países da América Central e Caribe: Peru, Bolívia e Belize. No mesmo período, no caso do Brasil a proporção passou de $8,4 \%$ para $9 \%$. Isso significa que para se alterar tais distorções ter-se-ia que corrigir o déficit em 35 anos (uma geração, segundo o referido estudo), desde que se mantivesse um incremento líquido, ou per capita, de 3,9\% a.a. (conf. Relatório Complexo Econômico Industrial da Saúde: a evolução e dinâmica de Arranjos e Sistemas Produtivos e Inovativos Locais no Brasil - O Caso do Pará, 2014).

\subsection{O sistema de ação social}

Desde o século XIX se desenvolveu uma corrente "higienista", logo após a descoberta de Pasteur sobre o papel dos micróbios na propagação das doenças. De acordo com essa corrente, representada notadamente pelo Doutor Villemé, não são os fatores ambientais que são responsáveis pelas causas das doenças e da mortalidade, mas as condições sociais, e em primeiro lugar a miséria e a moralidade ${ }^{11}$ das classes populares (VILLERME, 1840, reeditado em 1986). Essas concepções vão ter uma grande importância sobre as maneiras de abordar as questões de saúde. Elas deram origem à noção de sistema de saúde e, principalemente, à ideia de que a saúde não está vinculada a uma abordagem exclusivamente médica. As condições de trabalho, a alimentação, a habitação, a higiene corporal e os cuidados destinados às crianças serão considerados fatores fundamentais para a saúde das populações. Progressivamente, nas sociedades europeias, uma parte dessas questões será tratada pelas diversas políticas públicas: política de habitação, política de trabalho ou ainda política urbana. Todas essas políticas contribuíram para a construção do estado de saúde da população, ao

1 Este conceito se inscreve na perspectiva conservadora fortemente influenciada pela igreja católica e denuncia os comportamentos das classes populares: embriaguez e permissividade sexual em particular. 
mesmo tempo que a definição declarada pela OMS também corroborou para a construção da noção de "bem-estar" dessas pessoas.

O higienismo, portanto, salientou a importância das políticas públicas para promover o nível de saúde da população, mas também destacou uma série de fatores que dependem de abordagens individuais. Os componentes individuais no cotidiano, em relação à higiene corporal, práticas alimentares, cuidados às crianças etc., têm influencia considerável sobre a saúde. Ou essas "boas práticas" são desigualmente distribuídas. A introdução e a generalização dessas práticas supôem uma abordagem educativa a essas problemáticas higienistas com as familias, em particular direcionadas às classes populares. Esta será a missão do serviço social (PASCAL, 2014). As diferentes categorias de trabalho social que vão progressivamente construir o sistema de ação social acompanharão este trabalho pedagógico com as famílias das classes populares, permitindo rápido progresso na higiene e no cuidado às crianças. Mas eles favorecem igualmente o acesso ao sistema médico de saúde. Os trabalhadores sociais têm um papel de interface entre as questões de ordem social e sanitária. Esse papel é particularmente importante no sistema local de saúde, notadamente sobre as crianças de famílias monoparentais e de pessoas idosas. Importante também esses trabalhos sociais porque se articulam às diferentes redes sanitárias e sociais que existem em nível local.

O sistema local de saúde integra igualmente as abordagens de saúde das práticas e dos comportamentos tradicionais que a medicina oficial recusa reconhecer. Essas especificidades existem, com efeito, tanto na França como no Brasil.

$\mathrm{Na}$ França notadamente, apesar da tendência a certa homogeneização cultural, nós constatamos a permanência de práticas locais tradicionais. "Cortadores de fogo ${ }^{12 ", ~ " c u r a n d e i r o ", ~ " h i p n o t i z a d o r e s ", ~ " p u x a d o r e s ~ d e ~ o s s o s " ~ a i n d a ~ e s t a ̃ o ~}$ muito presentes nas práticas terapêuticas de populações particularmente em algumas áreas rurais. A medicina oficial é pressionada por essas práticas, mas não ignorada, muitos hospitais têm listas de "cortadores de fogo" e os acionam quando necessário, sugerindo discretamente aos pacientes (PERRET, 2009). Nas palavras do chefe do departamento de um hospital em Rodez (Aveyron): "Por mais de 30 anos eu direciono meus pacientes para curandeiros a fim de aliviar-lhes a dor: eu constatei que isso melhora seu estado. Eu devo recusar seus métodos por não saber como eles funcionam?" Essas práticas são igualmente muito difundidas em numerosas regiões como em Bretagne (CAMUS, 2013), Auvergne (RAINEAU, 2002) e Savoie (PERRET, 2009) ou ainda no sudoeste,

12 É uma prática de cura xamânica em que o xamã, através do toque das mãos e rezas, recupera e cura, ferimentos, torções musculares e luxações. 
assim como nos departamentos de além-mar (SALOMON, 2000).

No Brasil estudos já comprovaram que a ausência dessas práticas tradicionais de saúde tornaria os sistema público de saúde caótico (PEIRANO, 1980). Desnecessário dizer, além disso, que muitas das práticas de saúde indígena tem possibilitado até o dias de hoje a sobrevivência de inúmeros povos étnicos no Brasil e no mundo. Portanto, é em nível local que a integração dessas práticas se efetuam notamente por intermédio de um sistema social local.

\section{CONCLUSÃO}

Em muitos aspectos, Brasil e França parecem muito diferentes, na extensão, nível de riqueza e de desigualdade. No entanto, esta análise comparativa dos sistemas de saúde identificou muitos pontos em comum. A desigualdade em termos de territórios do estado de saúde ou o acesso aos cuidados é uma realidade na França e no Brasil e, a necessidade de uma abordagem territorial dos problemas é necessária em ambos os países para se entender a natureza desses problemas, mas também para promover soluções.

A análise revela, entretanto, importantes diferenças. Com efeito, se observa nos dois países numerosos dispositivos locais, mas suas modalidades de produção são, no entanto, contrastantes. O sistema francês parece revelar uma abordagem "bottom-up" mais do que uma abordagem "top-down", enquanto o inverso é verdadeiro no caso brasileiro. Isto ocorre sem dúvida porque no Brasil nós observamos uma distorção entre os modelos de ação juridicamente definidos e as ações aplicadas sobre diferentes realidades e contextos municipais diversos, em particular nos municípios da Amazônia.

O sistema local de saúde reflete as especificidades dos dois sistemas político-administrativos, francês e brasileiro. No Brasil, muitas vezes, é o governo federal que tem a iniciativa de estimular os sistemas de ações descentralizados, no entanto, têm dificuldades, em seguida, de implantá-los localmente. Na França, as iniciativas locais (por exemplo, a "casa de saúde"), depois de implantadas, encontraram um quadro jurídico nacional que reforçou a sua legitimidade, mas que também tende a fixar essa inovação em um dispositivo processual frequentemente muito pesado. O que a princípio era um dispositivo local, flexível e adaptado à realidade de um território torna-se uma espécie de instituição funcionando burocraticamente. Em ambos os casos, no entanto, a intervenção do Estado promove a sustentabilidade dos sistemas de ação local, mas também tende igualmente a reduzir a sua capacidade de resposta às mudanças. 


\section{REFERÊNCIAS}

ABRUCIO, F. L. Trajetória recente da gestão pública brasileira: um balanço crítico e a renovação da agenda de reformas. Rio de Janeiro. Edição Especial Comemorativa 67-86, 1967-2007.

BARUCH, M. O.; BEZES, P. Introduction. Généalogies de la réforme de l'Etat. Revue Française D’Administration Publique, v. 4, n. 120, p. 625-633, 2006.

BRASIL. Ministério da Saúde. Diretrizes operacionais dos Pactos pela Vida, em Defesa do SUS e de Gestão. Brasília: Ministério da Saúde. Secretaria de Políticas de Saúde. II. Título. III. Série, 2006.

Ministério da Saúde. Secretarian de Assitência à Sáude. Regionalização da assistência à saúde: aprofundando a descentralização com equidade no acesso: Norma Operacional da Assistência à Saúde: NOAS-SUS 01/01 e Portaria MS/GM $\mathrm{n}^{\circ}$ 95, de 26 de janeiro de 2001 e regulamentação complementar. Brasília, 2001.

- Lei 8.142, de 28 de dezembro de 1990: dispõe sobre a participação da comunidade na gestão do sistema único de saúde - SUS e sobre as transferências intragovernamentais de recursos financeiros na área da saúde e dá outras providências. Diário Oficial da União. Brasília, 1990.

. Lei 8.080, de 19 de setembro de 1990. Dispõe sobre as condições para a promoção e recuperação da saúde, a organização e funcionamento dos serviços correspondentes e dá outras providências. Diário Oficial da União. Brasília, 1990.

BURNS, T.; STALKER, G. M. The management of innovation. London: Tavistock, 1961.

CAMUS, D. Parole magiques: secrets de guérison. Paris: Ed. Imago, 1980. Réédit 2013.

COSTA, F. de A. (Coord.). Relatório Descritivo Final. Complexo Econômico Industrial da Saúde: a evolução e dinâmica de Arranjos e Sistemas Produtivos e Inovativos Locais no Brasil - O Caso do Pará, Belém, 2014.

DONZELOT, J.; ESTEBE, P. L'Etat animateur: essai sur la politique de la ville. Paris: Seuil, 1994.

EVANS, R. G.; BARER, M. L.; MARMO, T. R. Why are some people healthy and others not? The determinants of health of populations. New York: Aldine de Gruyter, 1994.

FALEIROS, V. de P. A reforma do Estado no período FHC e as propostas do governo Lula. In: FALEIROS, V. de P.; NUNES, S. P.; FLEURY, S. A era FHC e o governo Lula: transição? Edição Luciana Costa; Organização: Denise Rocha; Maristela Bernardo. Brasília: Instituto de Estudos Socioeconômicos, 2004. 
FERREIRA, J. R.; BUSS, P. M. Atenção primária e promoção da saúde. In: BRASIL. Promoção da Saúde. Brasília: PNUD; Ministério da Saúde, 2001. p. 7-14.

GARNELO, L. Globalização e ambientalismo: etnicidades polifônicas na Amazônia. História, Ciências, Saúde-Manguinhos, Rio de Janeiro, v. 12, n. 3, p. 755-767, 2006.

Política de saude dos povos indigenas no Brasil: análise situacional do período de 1990 a 2004. Documento de Trabalho n. 9, Universidade do Amazonas \& Centro de Pesquisas Leônidas e Maria Deane, Fundação Oswaldo Cruz, Manaus. Porto Velho, nov. 2004.

GIOVANELLA, L.; MENDONÇA, M. H. M. Saúde da família: limites e possibilidades para uma abordagem integral de atenção primária à saúde no Brasil. Ciência \& Saúde, v. 14, n. 3, p. 783-794, 2009.

GONÇALVES, R. F. Autonomia e sustentabilidade indígena: entraves e desafios das políticas públicas indigenistas do Estado do Pará entre os anos 1988-2008. 2010. Tese (Doutorado em Desenvolvimento Sustentável do Trópico Úmido) - Núcleo de Altos Estudos Amazônicos, Universidade Federal do Pará, Belém, 2010.

HASSENTEUFEL, P. Sociologie politique: l'action publique. Paris: Armand Colin, 2011.

IBGE. Esperança de vida ao nascer, 2013. Disponível em: http:/ / saladeimprensa. ibge gov.br $/$ noticias? view $=$ noticia\&id $=1 \&$ busca $=1 \&$ idnoticia $=2773$. Acesso em: dez. 2015.

Assistência médico-sanitária. Brasília: MAS, 2009.

INSEE. Évolution de l'espérance de vie à divers âges jusqu'en 2015. Disponível em: http://www.insee.fr/fr/themes/tableau.asp?reg_id=0\&ref_id=NATnon02229. Acesso em: 15 dez. 2016.

LAWRENCE, P. R.; LORSCH, J. W. Organization and environment: managing differentiation and integration. Boston: Harvard Business School Press,1967.

LE GALES, P.; THATCHER, M. (Dir.) Les réseaux de politique publique, débats autour des "policy networks", Paris: l'Harmattan, 1995.

MADEL, T. L. Notas sobre as políticas de saúde no Brasil de "transição democrática" - anos 80. PHYSIS - Revista de Saúde Coletiva, v. 1, n. 1, 1991.

MENDES, E. V. O cuidado das condições crônicas na atenção primária à saúde: o imperativo da consolidação da estratégia da saúde da família. Brasília: Organização Pan-Americana da Saúde, 2012. 
Uma agenda para a saude. 2. ed. São Paulo: Hucitec, 1999.

NUNES, D. E. Saúde coletiva: uma história recente de um passado remoto. In: CAMPOS, G. W. de S.; MINAYO, M. C. de S., et al. Tratado de saúde coletiva. São Paulo: HUCITEC; Rio de Janeiro: Fiocruz, 2006.

ONU. World Population Prospects: The 2013 Revision (Perspectives relatives à la population mondiale) New York: Nations Unis, 2014.

PASCAL, H. Histoire du travail social en France. Presses de l'EHESP Rennes 2014.

PEIRANO, M. A reima do peixe. Pesquisa Antropológica, Brasília, v. 21, p. 1-112, 1980.

PERRET, N. Place des coupeurs de feu dans la prise en charge ambulatoire et hospitalière des brûlures en Haute-Savoie en 2007. Human health and pathology. 2009.

RAINEAU, C. Maladie et infortune dans l'Auvergne d'aujourd'hui. Médecins, malades et guérisseurs d'un bourg montagnard à l'hôpital. Ruralia [En ligne], 10/11, 2002, mis en ligne le 25 juin 2003. Disponível em: http://ruralia.revues.org/309. Acesso em: 03 dez. 2015

SAINT PAUL, G. Réflexions sur l'organisation du système de santé. L'a Documentation Française, Paris: Direction de l'information légale et administrative, 2013

SALOMON, S. Savoirs et pouvoirs thérapeutiques kanaks. Paris: INSERM, Presses Universitaires de France, 2000. 154p.

TEISSERENC, P. Les politiques de développement local. 2. ed. Paris: Colletion Collectivités Territoriales dirigée par Louis Favoreu, Economica, 2002.

THOMÉ, A. M. T.; SOUZA, M. S.; CALHEIROS, O. Pesquisa sobre os condicionantes do sub-registro de nascimento em populações indígenas da Amazônia Legal Brasileira. Rio de Janeiro: BEMFAM, 2014.

UNGER, J. P. International health and aid policies. Londres: Cambridge University Press, dez. 2010.

VILLERME, L. R. Tableau de l'état physique et moral des ouvriers employés dans les manufactures de coton, de laine et de soie (2 volumes, 1840). Réédition sous le titre Tableaux de l'état physique et moral des salariés en France, Les Éditions La Découverte, Paris, 1986. 